Original Research Paper

\title{
An Assessment of the Effect of Education, In-Service Training (IST) and Tenure on Healthcare Performance: A Cost- Optimizing Perspective
}

\author{
${ }^{1}$ Nestor Asiamah, ${ }^{2}$ Henry Kofi Mensah and ${ }^{3}$ Eric Fosu Oteng-Abayie \\ ${ }^{1}$ Africa Centre for Epidemiology, Accra, Ghana \\ ${ }^{2,3}$ Kwame Nkrumah University of Science and Technology, Kumasi Ghana
}

Corresponding Author:

Nestor Asiamah

Africa Centre for

Epidemiology, Accra, Ghana

Email: nestor.asiamah@yahoo.com

\begin{abstract}
Healthcare institutions, governments and other stakeholders have over the years used employee education, in-service training and tenure prolongation to enhance the job performance of health professionals, which is termed healthcare performance in this study. The lack of adequate financial resources may however leave employers with the sole option of applying only one of these methods. This study attempts to identify the best predictor of healthcare performance that can be prioritized in cost-optimizing situations. Self-reported and supervisor- or superior-reported questionnaires were used to collect data from 1,163 health professionals in Accra North, who were selected using random sampling methods. Confirmatory Factor Analysis was used to test the study's hypotheses. The resulting model is of good fit at $5 \%$ significance level [Chi-square $\left(\chi^{2}\right)=1.492 ; \mathrm{p}=0.222$ ], with training found to be the ultimate method applicable if the need to use a single method arises. Nonetheless, the role of training as the ultimate applicable method is driven by tenure prolongation. The study concludes that in-service training is the ultimate method applicable for enhancing healthcare performance. Nevertheless, simultaneous application of training and tenure prolongation in non-financial or costoptimizing terms is recommended.
\end{abstract}

Keywords: Healthcare Performance, Education, Tenure Prolongation, InService Training, Job Performance

\section{Introduction}

One of humankind's greatest needs is good health, which is a requirement for happiness. Good health is an indicator of quality of life (Sun et al., 2008; Hitam and Borhan, 2012), which means that it is inevitably needed to maximize life satisfaction. At the individual level, health determines the capacity to work and fend for self, assist relations and meet national tax obligations. At the national level, the health condition of the citizenry influences productivity. This situation is attested to by the much theorized and empirically confirmed relationship between national health and Gross Domestic Product (GDP) or national wealth (Akram et al., 2011). It also forms the foundation of the vehemence with which governments, institutions such as the World Health Organization and individuals (e.g., public health professionals) are advocating for and working towards good health for all.

Over the years, public health stakeholders have instituted various measures to enhance the health of individuals and populations. Currently, climate change control has been incorporated in the framework of measures being applied to reverse the on-going damage to climate quality and environmental safety (Hitam and Borhan, 2012), which contributes to health and quality of life (Sun et al., 2008; Hitam and Borhan, 2012). Yet continuous healthcare quality and efficiency improvement remains an outstanding global agenda and has accounted for a significant part of expenditure on public health promotion across the world (Hitam and Borhan, 2012; Diab and Ajlouni, 2015).

In their quest to improve healthcare quality and efficiency, governments, health organizations and other 
stakeholders seek to improve the performance of healthcare professionals, particularly in terms of quantity and quality of work done (Yuxiu et al., 2011; Diab and Ajlouni, 2015). Some methods have been primarily deployed to achieve this goal. Theoretically, inservice training, formal education and tenure prolongation are the most applied methods for improving job performance. Researchers ( $\mathrm{Ng}$ and Feldman, 2009; Khan et al., 2016) have also opined that these three methods are those mostly applied by governments and healthcare organizations based on the idea that they make positive or incremental effect on the performance of health professionals.

Depending on whether or not each of these three methods make a positive effect on healthcare performance, situations may sometimes demand employers to prioritize one of them in practice. It may be argued that many governments are currently suffering from economic recession and hardship. Financial difficulties may consequently be faced by governments and institutions and this situation could give rise to the need to focus on the application of only one of these methods to optimize cost in enhancing healthcare performance.

Rationally, the method to prioritize or the ultimate method should be the best predictor of healthcare performance. Since correlation between each pair of the methods is possible, the best predictor will, at best, be identified in a Confirmatory Factor Analysis (CFA), which can simultaneously estimate the correlation between each pair of the three methods and their respective effects on healthcare performance. Moreover to ensure its reliability in practice, the best predictor (method) would have to be consistently confirmed in the CFA context across populations. In view of the absence of relevant empirical evidence in the literature, this study attempts to test a CFA model that provisionally identifies the ultimate method. As a foundational study, its findings serve as a baseline for identifying the ultimate method through academic debate.

\section{Literature Review}

Continuously improving healthcare performance, which is a responsibility of governments and health organizations, is necessary for maximizing health-related quality of life across the world. Yet global economic downturn could constrain the quest of governments and institutions to invest towards high healthcare performance. This assertion may be better understood after healthcare performance is operationally defined in this study based on the definition of job performance. One of the simplest definitions of job performance is "the extent to which a job is well done" (Campbell et al., 1993). Before this definition was coined, Campbell (1990) defined job performance as the outcome or result of reaching a goal or set of goals with respect to a job or role in an organization. Campbell (1990) nevertheless emphasized that job performance is not the actual consequences of the acts performed on a job.

Job performance is often used interchangeably with employee performance, which has been defined as "the degree to which employees perform job tasks assigned to them by their employers" (Kahya, 2007; Mozael, 2015). Substantial job performance thus means an employee has accomplished job-related responsibilities to a satisfactory extent or to a degree expected by his or her employer.

Health professionals are employees serving under either a government or private healthcare institution and are obliged and mandated to carry out job tasks relating to healthcare. Healthcare quality and effectiveness is consequently influenced by how well health professionals carry out these tasks. Based on the definitions of job performance presented earlier, healthcare performance is operationally defined in this study as: (a) How well health professionals accomplish job roles assigned to them by their employers; and (b) the extent to which job roles embodied by Schwirian (1978) scale are accomplished.

The original scale of Schwirian (1978) was developed for measuring nursing performance and serves as a construct of six dimensions; namely teaching and collaboration, planning and evaluation, critical care, interpersonal relations and communication, leadership and professional development. With respect to Schwirian (1978) original scale, high nursing performance is presented by large mean scores (i.e., the smallest score on the scale is 1 and the largest is 5) associated with each indicator of the six dimensions, which constitute all job tasks relating to the nursing profession (El Enein et al., 2012). Based on the adaptation of this scale by some researchers (Greenslade and Jimmieson, 2007; Yuxiu et al., 2011; El Enein et al., 2012), the sixdimension scale is appropriate for measuring the job performance of other health professionals. This study therefore treats healthcare performance as a construct of the six-dimension scale of Schwirian (1978), which is however modified through rewording based on the recommendation of its originator.

Continuous enhancement of healthcare performance is important and falls within the framework of global public health goals. As mentioned earlier, In-Service Training (IST), tenure prolongation and formal education are some of the main methods often used to enhance healthcare performance. The application of these methods as job performance enhancement methods could be justified from the point of view of the Job Characteristic Theory (JCT). The JCT was formulated by Hackman and Oldham (1975) and posits that performance, precisely job performance, is a variable 
that can be predicted by five core variables; namely skill variety, task identity, task significance, autonomy and feedback. The theory assumes that the level of job performance can change when these five predictors change individually and as a group. In terms of the first predictor (i.e., skill variety) for example, the JCT asserts that job performance is more likely to be higher if a job requires the deployment of a higher variety of skills.

It is contended in this study that there are basic determinants of the variety of skills that a personnel can deploy on the job to engender satisfactory performance. Though the individual is born with several skills (Goleman, 1995), education is one of the determinants or drivers of the variety of skills and competencies possessed by an individual. In other words, each level of education acquired can equip the individual with new skills and knowledge needed to carry out job tasks. This argument is supported by some studies (Kahya, 2007; Ng and Feldman, 2009) by confirming the positive effect of educational level on job performance, though these studies were not focused on health professionals. It is therefore argued that improving the education of health professionals can enhance healthcare performance. The first hypothesis of this study is therefore formulated as follows:

\section{H1- Formal education makes a positive effect on job performance so that healthcare performance increases when the level of education of health professionals increases.}

Skill variety can also be determined by in-service training, which is a more specialized approach to enhancing the competencies of personnel or equipping them with new skills and knowledge. Employees with more training are therefore likely to have more relevant competencies to savor on the job. Basically, corporate training programs are motivated by this idea. Moreover, many studies (EL Enein et al., 2012; Alfandi, 2016; Khan et al., 2016) have found that job performance increases with the level of access to in-service training. In this study it is argued that this finding could apply to health professionals as well. This study therefore poses its second hypothesis as follows:

\section{H2- Level of engagement in IST makes a positive effect on job performance so that healthcare performance increases when the number of ISTs health professionals participate in increases.}

A third factor that can determine skill variety is tenure or the number of years a personnel has spent on the job. To explain, being an employee is an opportunity to build experience and improve competencies in accomplishing job tasks in the passing of time, especially routine tasks. To add, less competent health professionals can learn from colleagues and job experiences on the job over time to become more competent. For these reasons, health professionals who have spent more years on the job are more likely to have a richer variety of skills and the ability to carry out job tasks in the light of these skills. As a result, tenure can make a positive effect on job performance, an assertion supported by the confirmation of this relationship in some studies (Kahya, 2007; Jehanzeb and Bashir, 2013) outside the healthcare sector. The third hypothesis of this study is therefore given as follows:

\section{H3- Tenure makes a positive effect on job performance so that healthcare performance increases as health professionals spend more years on the job.}

The importance of this study is partly expressed by the fact that no identifiable individual study has tested the effect of education, tenure and IST on healthcare performance in a single CFA model in which their correlations are simultaneously examined. Meanwhile these correlations might influence the effects of these three predictors on healthcare performance and could therefore play a critical role in empirically identifying the ultimate method.

Traditionally, formal educational programs are enriched with various forms of human development activities, including academic training, mentoring and coaching. Though these education-driven activities of human development may not be designed to address health professionals' specific job roles, they can enhance their general level of competency; enabling them to better carry out job tasks. Hence, as formal education and its expected effect on health workers increases, it can overshadow the need for employees to participate in IST. From this viewpoint, education would make a negative effect on IST so that increased level of education decreases the level of IST engaged in.

On the other hand, IST can be used to empower employees to enhance job security through high performance. Invariably, high performing employees are more likely to spend more years on the job and consequently obtain support (e.g., funding or scholarship) from their organizations to pursue higher education. From this perspective, IST would make a positive effect on educational level. The study therefore tests the following fourth hypothesis:

\section{H4- Education makes a significant correlation with the level of IST received by health professionals.}

Primarily, tenure is influenced by the career development opportunities given to the health 
professional. However, access to higher education as well as frequent in-service training can enable a personnel to accomplish job roles better and consequently empower him to achieve job security. From this perspective, tenure is positively influenced by educational level and IST. From another viewpoint, health professionals who have spent more years on the job might be considered loyal to the organization; for which management may be willing to support their further education by providing scholarship, approving their study leave, to mention but a few. From this perspective, tenure would make a positive effect on educational level and IST. On the basis of these understandings, the following last two hypotheses are tested in this study:

\section{H5- There is a significant relationship between educational level and tenure H6- There is a significant relationship between tenure and in-service training}

The last three hypotheses (i.e., H4, H5 and H6) do not reflect the Dependent Variables (DVs) and Independent Variables (IVs). However, based on the perspectives from which these hypotheses are developed in this study, the DVs and IVs can be known depending on whether or not the respective correlations of the three hypotheses are negative or positive. The nature of these correlations would also determine which of the three variables (i.e., education, tenure and IST) best predicts healthcare performance and therefore potentially constitutes the ultimate method for enhancing healthcare performance.

\section{Methods}

This study adopted a cross-sectional quantitative research technique in order to test the hypotheses using a CFA model. The study's participants were health professionals and their respective supervisors or superiors serving in healthcare institutions (i.e., clinics, polyclinics and hospitals) in Accra North, Ghana. The accessible population of this study was health workers and their respective superiors or supervisors who were available to complete questionnaires and were working in healthcare institutions registered and controlled by Ghana Health Service (GHS). Health professionals in institutions not controlled by GHS were not incorporated in the population because in most cases, they are not formally trained based on GHS standards and are not officially recognized as health workers in Ghana. Moreover, the accessible population did not include cleaners, security officers and administrative workers who did not engage directly with patients and their relations. Table 1 shows the accessible population size across the ten hospitals.
Table 1: Population and sample sizes of the study

\begin{tabular}{lll}
\hline Hospital name & Population size $(\mathrm{N})$ & Sample size (s) \\
\hline Ridge Hospital & 345 & 181 \\
37 Military Hospital & 267 & 159 \\
Iran Clinic & 133 & 97 \\
Mamobi Polyclinic & 123 & 92 \\
Adabraka Polyclinic & 132 & 97 \\
Cocoa Clinic & 104 & 80 \\
Holy Trinity Hospital & 243 & 148 \\
Kaneshie Polyclinic & 178 & 123 \\
Achimota Hospital & 156 & 113 \\
Total Clinic & 92 & 73 \\
Total & $1,773.00$ & $1,163.00$ \\
\hline
\end{tabular}

NOTE: The population and sample sizes in Table 1 represent health workers who were available at the time of the study. The superior or supervisor of each of these workers was also available at the time of the study

To provide a basis for generalizing findings to the population, a sample of 1,163 health workers was drawn from the accessible population. A superior or supervisor could only participate in this study if his or her subordinate(s) was initially selected as a participating health worker. So supervisors and superiors were reached after selecting health workers in the sampling process. In the sampling process, a representative number of health workers was drawn from each institution using the simple random sampling method. Table 1 shows the sample sizes drawn from each hospital and the overall sample size. Moreover, the sample sizes drawn are determined using the standard sample size determination table of Krejcie and Morgan (1970). The researchers used the sample size determination table of Krejcie and Morgan (1970) in view of the fact that its sample sizes were calculated using a relatively large population proportion of 5\% and therefore provides access to the most representative sample. In sampling from each healthcare organization, the researchers simulated numbers in MS Excel 2013 and assigned them to health workers who constituted the accessible population. Simulated numbers were exported to SPSS Version 21, where the random sampling function was activated and used to select participants from each hospital at random.

The study adopted Schwirian (1978) nursing performance scale to measure healthcare performance through a supervisor- or superior-reported questionnaire, though the scale was slightly reworded to assess the roles of all health workers. This scale was employed because it is well validated and is consistent with other measures of performance in the healthcare sector (Greenslade and Jimmieson, 2007; Yuxiu et al., 2011; El Enein et al., 2012). To minimize respondent bias, each worker's superior or supervisor (rather than the worker) was asked to indicate the extent of performance of his or her specified subordinate(s) based on the 52 items of the measurement scale. Items 
of HP was associated with five levels of response: Strongly disagree (1); disagree (2); not sure (3); agree (4); and strongly agree (5). Verifiable from the data analysis is the fact that reliability and validity of this scale was confirmed to be appreciable.

Unlike healthcare performance, the predictors were measured through a questionnaire completed by sampled health workers. Education was measured as a categorical variable, while training and tenure were measured as continuous variables. Education was measured in terms of the highest level of education acquired by a health professional, whereas IST was measured in terms of the number of training and development programs a health professional had participated in since he or she was formally employed. Tenure was measured in terms of how long (in years) a health professional had served on the job. Education was associated with the following levels of response: Basic qualification (1), secondary qualification (2), diploma (3), first degree (4), second degree (5) and $\mathrm{PhD}$ and higher (6).

A committee of individuals from the ten participating hospitals approved the ethical considerations of the study. Data was collected within twenty-eight (28) working days using hand delivery. Each health worker and subordinate or supervisor also formally agreed to participate by signing an informed consent form. Data was collected with the assistance of three hired persons. Within each healthcare institution, an administrative worker appointed by the head of administration guided and led questionnaire administration. Out of 1,163 questionnaires administered, 848 were returned by respondents. However, 37 returned questionnaires had major response and non-response errors and were therefore discarded. Thus, 811 questionnaires were analyzed. The researchers achieved fairly substantial representation of individuals at each level of the categorical predictors (refer to Table 2).

In data analysis, CFA was used to validate the measurement scale. The validation process involved the estimation of the scale's level of reliability and validity. Table 3 shows results of the validation. In this table, each dimension or factor of HP has CA and $\mathrm{CR}$ values greater than the baseline value of 0.7 recommended by researchers (Morse 2002; Drost, 2011). Thus, the HP scale is internally consistent. The ICC values and their corresponding $p<0.05$ results also suggest that the HP scale is reliable. AVE is an indicator of convergent validity of the scale, whereas MSV and AVS statistics are used to assess its discriminant validity. From Table 3 , the AVE $>0.5$, $\mathrm{CR}>\mathrm{AVE}, \mathrm{MSV}<\mathrm{AVE}$ and $\mathrm{ASV}<\mathrm{AVE}$ criteria recommended by researchers (Hurley et al., 1997; Schutte et al., 1998) are met for all factors. Therefore, the HP scale has appreciable convergent and discriminant validity. The CFA retains all 52 items of the scale (refer to Table 5 for indictors of the scale).

Table 2: Number of Participants at each Level of the Categorical Predictors

\begin{tabular}{llll}
\hline Variable & Level & Frequency & Percent \\
\hline Gender & Male & 284 & 35 \\
& Female & 527 & 65 \\
Education & Total & 811 & 100 \\
& Diploma & 256 & 31.6 \\
& First degree & 403 & 49.7 \\
& Master's degree & 152 & 18.7 \\
\hline
\end{tabular}

Table 3: Reliability and Validity Statistics for the HP Scale

\begin{tabular}{|c|c|c|c|c|c|c|c|c|c|}
\hline \multirow[b]{3}{*}{ Factor } & & & \multicolumn{4}{|c|}{$\mathrm{ICC}$} & \multirow[b]{3}{*}{ AVE } & \multirow[b]{3}{*}{ MSV } & \multirow[b]{3}{*}{ ASV } \\
\hline & & & \multirow[b]{2}{*}{$\begin{array}{l}\text { Single } \\
\text { measure }\end{array}$} & \multicolumn{2}{|c|}{$\mathrm{CI}$} & \multirow[b]{2}{*}{$\mathrm{p}$-value } & & & \\
\hline & $\mathrm{CA}$ & $\mathrm{CR}$ & & $\begin{array}{l}\text { Lower } \\
\text { limit }\end{array}$ & $\begin{array}{l}\text { Upper } \\
\text { limited }\end{array}$ & & & & \\
\hline Factor 1 & 0.765 & 0.722 & 0.275 & 0.231 & 0.320 & 0.000 & 0.501 & 0.001 & 0.0002 \\
\hline Factor 2 & 0.733 & 0.692 & 0.293 & 0.229 & 0.355 & 0.000 & 0.488 & 0.137 & 0.0158 \\
\hline Factor 3 & 0.743 & 0.701 & 0.127 & 0.058 & 0.194 & 0.000 & 0.167 & 0.165 & 0.0106 \\
\hline Factor 4 & 0.874 & 0.825 & 0.464 & 0.409 & 0.417 & 0.000 & 0.511 & 0.165 & 0.0230 \\
\hline Factor 5 & 0.822 & 0.775 & 0.252 & 0.187 & 0.318 & 0.000 & 0.321 & 0.137 & 0.0144 \\
\hline Factor 6 & 0.776 & 0.732 & 0.240 & 0.217 & 0.265 & 0.000 & ------- & ------- & ------- \\
\hline
\end{tabular}

KEY: CA = Chronbach's alpha; $\mathrm{CR}=$ Composite reliability; ICC $=$ Intra-class correlations; $\mathrm{CI}=$ Confidence interval; $\mathrm{AVE}=$ Average Variance Estimate; MSV = Maximum Shared Squared Variance; AVS = Average Shared Squared Variance 
Table 4: Descriptive Statistics Associated with Indicators of Healthcare Performance

\begin{tabular}{|c|c|c|c|c|c|c|c|}
\hline Indicator & Mean & Std. Dev. & $\mathrm{N}$ & Indicator & Mean & Std. Dev. & $\mathrm{N}$ \\
\hline NP1 & 4.19 & 0.74 & 811 & HP27 & 4.15 & 0.99 & 811 \\
\hline HP2 & 4.06 & 0.85 & 811 & HP28 & 4.03 & 0.83 & 811 \\
\hline HP3 & 4.19 & 0.82 & 811 & HP29 & 4.04 & 1.01 & 811 \\
\hline HP4 & 4.20 & 1.03 & 811 & HP30 & 4.13 & 0.92 & 811 \\
\hline HP5 & 3.98 & 0.9 & 811 & HP31 & 4.20 & 0.92 & 811 \\
\hline HP6 & 4.02 & 0.85 & 811 & HP32 & 3.92 & 1.05 & 811 \\
\hline HP7 & 4.16 & 0.74 & 811 & HP33 & 4.09 & 0.87 & 811 \\
\hline HP8 & 4.13 & 0.75 & 811 & HP34 & 4.05 & 0.94 & 811 \\
\hline HP9 & 4.18 & 0.74 & 811 & HP35 & 4.13 & 0.78 & 811 \\
\hline HP10 & 4.03 & 0.84 & 811 & HP36 & 4.03 & 0.93 & 811 \\
\hline HP11 & 3.99 & 1.11 & 811 & HP37 & 4.10 & 0.80 & 811 \\
\hline HP12 & 4.13 & 0.96 & 811 & HP38 & 3.81 & 1.09 & 811 \\
\hline HP13 & 4.08 & 0.87 & 811 & HP39 & 3.91 & 0.91 & 811 \\
\hline HP14 & 4.04 & 0.92 & 811 & HP40 & 3.87 & 1.06 & 811 \\
\hline HP15 & 4.08 & 0.95 & 811 & HP41 & 4.14 & 0.89 & 811 \\
\hline HP16 & 4.04 & 1.19 & 811 & HP42 & 4.23 & 0.60 & 811 \\
\hline HP17 & 3.92 & 0.92 & 811 & HP43 & 4.06 & 0.85 & 811 \\
\hline HP18 & 3.66 & 1.06 & 811 & HP44 & 3.91 & 0.98 & 811 \\
\hline HP19 & 4.04 & 1.15 & 811 & HP45 & 4.06 & 1.05 & 811 \\
\hline HP20 & 3.99 & 1.09 & 811 & HP46 & 3.93 & 0.84 & 811 \\
\hline HP21 & 4.35 & 0.81 & 811 & HP47 & 4.14 & 0.99 & 811 \\
\hline HP22 & 4.33 & 0.74 & 811 & HP48 & 4.20 & 0.98 & 811 \\
\hline HP23 & 4.28 & 0.57 & 811 & HP49 & 4.16 & 1.09 & 811 \\
\hline HP24 & 4.23 & 1.00 & 811 & HP50 & 4.22 & 0.69 & 811 \\
\hline HP25 & 4.09 & 0.86 & 811 & HP51 & 4.24 & 0.82 & 811 \\
\hline \multirow[t]{2}{*}{ HP26 } & 4.15 & 0.91 & 811 & HP52 & 4.12 & 0.85 & 811 \\
\hline & & & & HP & 4.08 & 0.91 & 811 \\
\hline
\end{tabular}

NOTE: Healthcare Performance (HP) is at a level of 4.08 (i.e., Mean $=4.08$; Std. Dev. $=0.91 ; \mathrm{N}=811$ ) out of a total expected level of 5 . The general level of healthcare performance in the region is therefore substantial, though improvement can be made and is needed.

The Box Plot was used to visualize the data to spot potential outliers and non-normality of the data. CFA was used to screen the data for outliers at a more robust level. Results of the CFA showed that none of the p2 values associated with the Mahalanobis distance test is less than 0.05 - the smallest of the p2 values is 0.199 . Data normality was therefore confirmed. To be able to test the hypotheses, an iterative CFA was started based on an over-identified model, enabling the researchers to reach a well fitted model. To avoid under-identification in the CFA, gender was introduced as a dummy predictor of healthcare performance.

Table 4 shows the descriptive statistics, including mean scores, associated with the indicators of healthcare performance. From this table, every item has a mean score within the range of the minimum and maximum values of the measurement scale, which are respectively 1 and 5. Moreover, the standard deviation associated with each indicator is small. These evidences corroborate the normality of data. Moreover, the corresponding mean of each indicator in Table 1 is close to the maximum value of the measurement scale, 5. Hence, the level of healthcare performance is considerably high.

\section{Results}

Table 6 shows a Pearson's correlation matrix of relevant variables. In this table, Healthcare Performance (HP) is significantly correlated to gender (Pearson's R = $0.150, p=0.000$ ) and tenure (Pearson's $R=0.191, p=$ 0.000 ) at $1 \%$ significance level, though these correlations are weak. The correlation between training and HP is also significant at the same level of significance (Pearson's $\mathrm{R}=0.248, \mathrm{p}=0.000$ ). Education makes no significant correlation with $\mathrm{HP}$ at $1 \%$ significance level $(\mathrm{R}=0.048, \mathrm{p}=0.168)$.

With reference to Table 7, Discrepancy stands for the chi-square value, the primary statistic of absolute fit. For a well fitted model, this chi-square value should be as small as possible and its p-value must be greater than the $5 \%$ cutoff value (Petrides and Furnham, 2000). On the basis of the fact that these criteria are met, the CFA has a good fit [Chi-square $\left(\chi^{2}\right)=1.492, \mathrm{p}=0.222$ ). In addition, Schutte et al. (1998) indicated that the Random Mean Square Error of Approximation (RMSEA) and Tucker-Lewis Index (TLI) values are required to be less than 0.06 and greater than 0.95 respectively if the CFA model has a good fit. In Table 7, these criteria are also met. 
Table 5: Indicators of the measurement scale

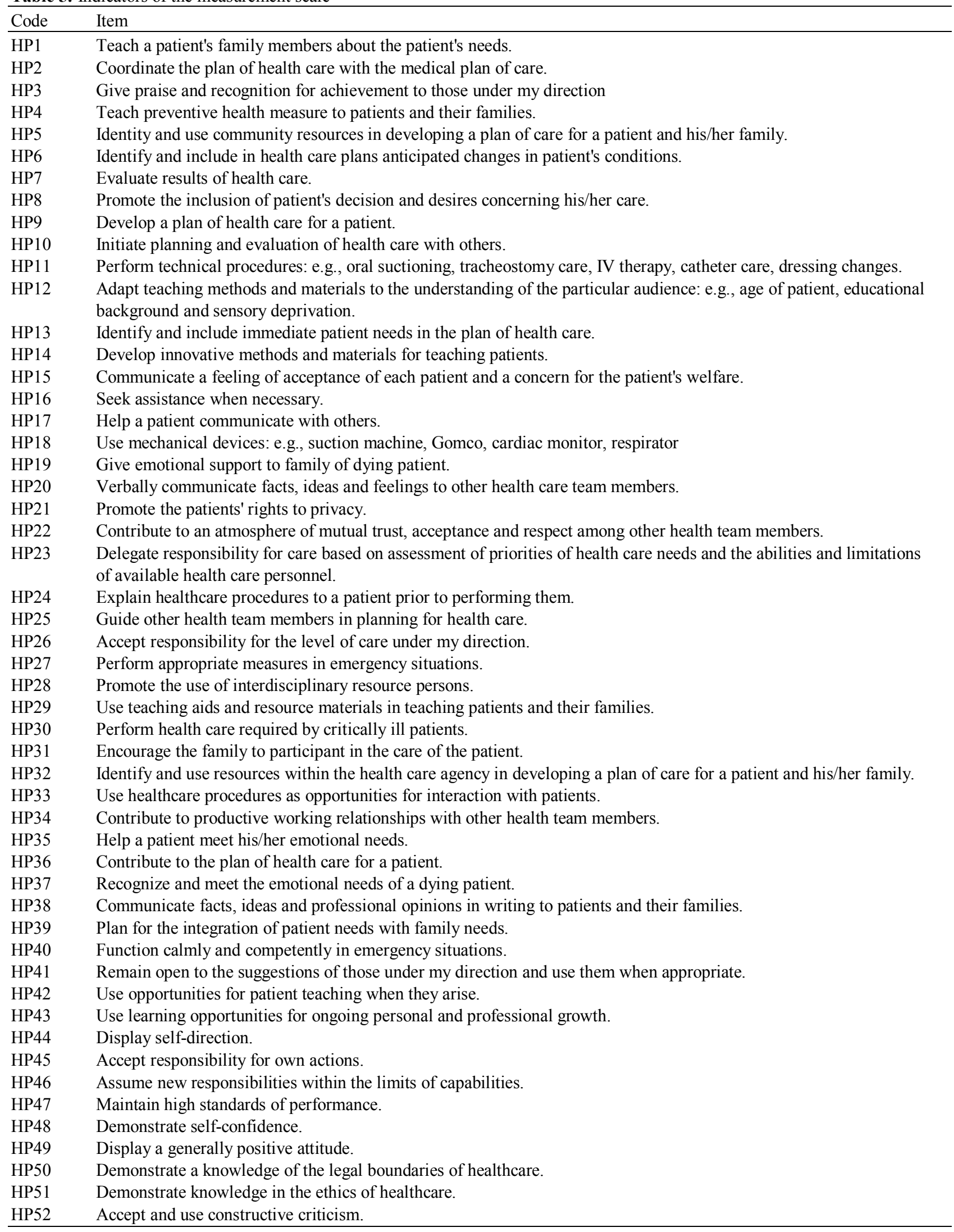


Nestor Asiamah et al. / Current Research in Psychology 2016, 7 (2): 16.26 DOI: 10.3844/crpsp.2016.16.26

Table 6: Pearson's Correlation Matrix

\begin{tabular}{|c|c|c|c|c|c|c|}
\hline & Gender & Education & Tenure & Training & $\mathrm{HP}$ & \\
\hline \multirow[t]{3}{*}{ Gender } & $\mathrm{R}$ & 1 & $-0.139^{* *}$ & $0.162^{* *}$ & 0.043 & $0.150^{* *}$ \\
\hline & p-value & & 0.000 & 0.000 & 0.222 & 0.000 \\
\hline & $\mathrm{N}$ & & 811 & 811 & 811 & 811 \\
\hline \multirow[t]{3}{*}{ Education } & $\mathrm{R}$ & & 1 & $0.081^{*}$ & $0.260^{* *}$ & 0.048 \\
\hline & p-value & & & 0.021 & 0.000 & 0.168 \\
\hline & $\mathrm{N}$ & & & 811 & 811 & 811 \\
\hline \multirow[t]{3}{*}{ Tenure } & $\mathrm{R}$ & & & 1 & $0.587^{* *}$ & $0.191^{* *}$ \\
\hline & p-value & & & & 0.000 & 0.000 \\
\hline & $\mathrm{N}$ & & & & 811 & 811 \\
\hline \multirow[t]{3}{*}{ Training } & $\mathrm{R}$ & & & & 1 & $0.248^{* *}$ \\
\hline & p-value & & & & & 0.000 \\
\hline & $\mathrm{N}$ & & & & & 811 \\
\hline \multirow[t]{3}{*}{ HP } & $\mathrm{R}$ & & & & & 1 \\
\hline & p-value & & & & & \\
\hline & $\mathrm{N}$ & & & & & \\
\hline
\end{tabular}

** Significant at 1\% significance level (2-tailed); * Significant at 5\% significance level (2-tailed)

Table 7: CFA Fit Statistics

\begin{tabular}{lcr}
\hline Measure & Default & Independence \\
\hline Discrepancy/ $\left(\chi^{2}\right)$ & 1.492 & 516.943 \\
P-value & 0.222 & 0.000 \\
DF & 1.000 & 10.000 \\
TLI & 0.990 & 0.000 \\
RMSEA & 0.025 & 0.250 \\
\hline
\end{tabular}

KEY: DF = Degree Of Freedom; TLI = Tucker-Lewis Index; RMSEA = Random Mean Square Approximation

Note: Level of significance applied $=0.05$

Table 8: Unstandardized Regression Estimates of the Fitted Model

\begin{tabular}{llllllll}
\hline Estimate & DV & Path & IV & Estimate & S.E. & C.R. & P \\
\hline Weights & HP & $<---$ & Gender & 8.257 & 2.116 & 3.901 & 0.000 \\
& HP & $<---$ & Education & 0.317 & 1.482 & 0.214 & 0.831 \\
& HP & $<---$ & Tenure & 0.972 & 0.966 & 1.005 & 0.315 \\
& HP & $<---$ & Training & 2.867 & 0.574 & 4.997 & 0.000 \\
\hline Covariance & Tenure & $<-->$ & Training & 1.633 & 0.113 & 14.432 & 0.000 \\
& Education & $<-->$ & Training & 0.409 & 0.055 & 7.394 & 0.000 \\
& Gender & $<-->$ & Education & -0.05 & 0.011 & -4.368 & 0.000 \\
& Gender & $<-->$ & Tenure & 0.084 & 0.018 & 4.75 & 0.000 \\
& Education & $<-->$ & Tenure & 0.074 & 0.031 & 2.372 & 0.018 \\
\hline
\end{tabular}

KEY: DV = Dependent Variable, IV = Independent Variable; S.E. = Standard Error; C.R. Critical Ratio; P = p-value or level of significance; NOTE: $D V$ and IV apply to only the 'Weights' main row

Table 8 shows the coefficients of the fitted model. In terms of the regression weights, gender makes a significant effect on $\mathrm{HP}$ at $1 \%$ significance level $\left(\beta_{\text {gender }}\right.$ $=8.257 ; \mathrm{p}=0.000)$. Training also makes a significant effect on HP at the same level of significance $\left(\beta_{\text {IST }}=\right.$ $2.867 ; \mathrm{p}=0.000)$. This result means that healthcare performance increases as training is enhanced or increased. Education and tenure however fail to predict $\mathrm{HP}$ at the same level of significance. Consequently $\mathrm{H} 2$ is supported by the data whilst $\mathrm{H} 1$ and $\mathrm{H} 3$ are not. In terms of the covariance estimates, there is a significant positive correlation between the following pairs of variables at $5 \%$ significance level: Tenure-IST (Estimate $=1.63, \mathrm{p}=0.000$ ); education-IST (Estimate $=0.409, \mathrm{p}=0.000)$; education-tenure (Estimate $=$ $0.074, \mathrm{p}=0.018)$; and gender-tenure $($ Estimate $=0.084$, $\mathrm{p}=0.000)$. The strongest correlation exists between tenure and IST. The only significant negative correlation exists between gender and education. The data therefore supports the last three hypotheses (i.e., H4, H5 and H6).

\section{Discussion}

According to results of data analysis, IST makes a positive effect on healthcare performance. This finding suggests that in-service training makes an incremental effect on healthcare performance. Interestingly, this finding supports a good number of studies in the literature (Tahir et al., 2014; Diab and Ajlouni, 2015; Khan et al., 2016). Noteworthy is the strong positive correlation between tenure and IST, which is likely to 
maximize the effect of IST on healthcare performance. Invariably, tenure prolongation could empower training to positively influence healthcare performance. It is therefore logical to say that training better impacts performance when tenure is prolonged.

Tenure and education, though significantly correlated to $\mathrm{HP}$, do not significantly predict healthcare performance. This being the case, the study's data does not support the hypotheses that tenure prolongation and education makes incremental effect on healthcare performance. Based on the opinion of some researchers conducted outside the health sector ( $\mathrm{Ng}$ and Feldman, 2009; Tiraieyari and Uli, 2011), this finding is consistent with the literature and also refutes some studies. This is to say that there are mixed evidences in the literature with respect to the effect of tenure and education on healthcare performance and this study supports the collection of studies that failed to confirm this relationship.

The insignificant effect of tenure on HP seems to imply that tenure prolongation does not make the expected effect on healthcare performance. Tenure prolongation is however relevant to healthcare performance owing to its large influence on IST that might have made it possible for in-service training to make a significant positive effect on HP in the CFA model. Thus in harmony with empirical evidences reached in previous studies ( $\mathrm{Ng}$ and Feldman, 2009; Yuxiu et al., 2011), a longer tenure is needed for health professionals to be impacted by in-service training programs. Also in view of the significant education-tenure correlation, which is consistent with some studies (Tiraieyari and Uli, 2011; $\mathrm{Ng}$ and Feldman, 2009), health professionals who have spent more years on the job are considered loyal to the organization; for which management may be willing to support their further education by providing scholarship and other forms of support.

In a nutshell, the CFA model reveals IST as the only predictor of healthcare performance in harmony with several studies acknowledged earlier. But the need to promote tenure prolongation, at least by using nonfinancial approaches, is a requirement for the positive effect of IST on healthcare performance.

\section{Conclusion}

This study finds that healthcare performance in Accra North is considerably high. Training, education and tenure are significantly correlated with healthcare performance. In the CFA model, only in-service training makes a significant positive effect on healthcare performance, suggesting that an increase in in-service training leads to healthcare performance improvement.
The positive effect of in-service training on healthcare performance is evidently traced to tenure on the basis of the strong positive IST-tenure correlation. Since the IST-tenure correlation is positive, it is evident that tenure causes an increase in access to training so that the higher the number of years served on the job, the better a professional's access to in-service training. Moreover, the IST-tenure correlation could be the basis of the effect of IST on healthcare performance in the CFA. Hence, the insignificance of the effect of tenure on HP in the CFA does not suggest that tenure prolongation or enhancement is not an applicable method for enhancing healthcare performance-tenure prolongation plays an important indirect role. By implication, employers and health organizations must accompany IST with tenure prolongation programs in order to achieve and maximize the incremental influence of IST on HP.

A significant positive correlation is found between education and in-service training. This outcome suggests that in-service training empowers employees to enhance job security and tenure through high performance and as a result obtain support (e.g., funding, study leave approval) from their organizations to pursue higher education. This point of view is also supported by the confirmed correlation between education and tenure.

It is therefore concluded that IST is the ultimate method for enhancing HP; however it would not be effective if not coupled with tenure prolongation programs. Hence, governments, employers and health organizations would have to implement IST and tenure prolongation programs simultaneously, though they reserve the right to use non-financial or costoptimizing tenure prolongation programs. Similarly, the interest of health workers to improve their education over time and to prolong their tenure by securing their job must still be supported by employers, at least in non-financial terms.

\section{Limitations of the Study}

Job performance is ideally assessed using objective measures, whereas subjective measures are vulnerable to respondent bias. Unfortunately, this study employed subjective measures or a superior/supervisor-reported scale as a result of the fact that the use of objective measures was not supported by some research conditions (e.g. the large sample size, the fact that objective measures could not be used). The researchers admit that the use of only a supervisor- or superior-reported scale for measuring performance is less rigorous. The researchers also admit that potentially relevant moderation and mediation effects were not tested in this study. A replication of this study for the purpose of addressing these limitations is therefore important. 


\section{Acknowledgment}

The researchers wish to acknowledge Panyan Bodong and his colleagues at New Ebirem Government Hospital for their assistance in data collection. They are also grateful to Ramson Etornam Ohene for proofreading our manuscript.

\section{Funding Information}

Funds were not obtained from any individual or institution for conducting this study.

\section{Author Contributions}

Nestor Asiamah: Conceived the research idea, designed the study, led data collection and analyzed the data.

Henry Kofi Mensah: Reviewed the literature and developed the study's introduction.

Eric Fosu Oteng-Abayie: Discussed the results, reviewed the analysis conducted by Nestor Asiamah, concluded the study and compiled the manuscript. Each researcher proofread the compiled manuscript.

\section{Conflict of Interests}

The researchers declare no conflicts of interest.

\section{Ethics}

This study was carried out by the researchers based on the approval of the various hospitals that participated in it. It has also not been published in any peer-reviewed journal or related platform.

\section{References}

Akram, A., M.A. Faheem, M.K. Dost and I. Abdullah, 2011. Globalization and its impacts on the World Economic Development. Int. J. Bus. Soc. Sci., 2: 291-297.

Alfandi, A.M., 2016. Training impact on the performance of employees "a case of Jordanian travel and tourism institutions". Int. Bus. Manage., 10: 377-384. DOI: 10.3923/ibm.2016.377.384

Campbell, J.P., 1990. Modeling the Performance Prediction Problem in Industrial and Organizational Psychology. In: Handbook of Industrial and Organizational Psychology, Dunnette, M.D. and L.M. Hough (Eds.), Consulting Psychologists Press, Inc., Palo Alto, CA., pp: 687-732.

Campbell, J.P., R.A. McCloy, S.H. Oppler and C.E. Sager, 1993. A Theory of Performance. In: Personnel Selection in Organizations, Schmitt, N. and W.C. Borman (Eds.), Jossey-Bass, San Francisco, pp: 35-70.

Drost, E.A., 2011. Validity and reliability in social science research. Educ. Res. Perspectives, 38: 105-123.
Diab, S.M. and M.T. Ajlouni, 2015. The influence of training on employee's performance, organizational commitment and quality of medical services at Jordanian private hospitals. Int. J. Bus. Manage., 10: 117-127.

El Enein, N.Y.A., A.S.A. El Ghany and A.A. Zaghloul, 2012. Knowledge and performance among nurses before and after a training program on patient falls. Open J. Nurs., 2: 358-364. DOI: $10.4236 /$ ojn.2012.24053

Goleman, D., 1995. Emotional Intelligence, Bantam Books, Inc., New York.

Greenslade, J.H. and N.L. Jimmieson, 2007. Distinguishing between task and contextual performance for nurses: Development of a job performance scale. J. Adv. Nurs., 58: 602-611. DOI: $10.1111 /$ j.1365-2648.2007.04256.x

Hackman, J.R. and G.R. Oldham, 1975. Development of the job diagnostic survey. J. Applied Psychol., 60: 159-170. DOI: $10.1037 / \mathrm{h} 0076546$

Hitam, M.B. and H.B. Borhan, 2012. FDI, growth and the environment: Impact on quality of life in Malaysia. Proc. Soc. Behav. Sci., 50: 333-342. DOI: $10.1016 /$ j.sbspro.2012.08.038

Hurley, A.E., T.A. Scandura, C.A. Schriesheim, M.T. Brannick and A. Seers et al., 1997. Exploratory and confirmatory factor analysis: Guidelines, issues and alternatives. J. Organiz. Behav., 18: 667-683. DOI: $\quad 10.1002 /(\mathrm{SICI}) 1099$ 1379(199711)18:6<667::AID-JOB874>3.0.CO;2-T

Jehanzeb, K. and N.A. Bashir, 2013. Training and development program and its benefits to employee and organization: A conceptual study. Eur. J. Bus. Manage., 5: 243-254.

Kahya, E., 2007. The effects of job characteristics and working conditions on job performance. Int. J. Indust. Ergonom., 37: 515-523. DOI: $10.1016 /$ j.ergon.2007.02.006

Khan, A.A., S.O.B.H. Abbasi and R.M. Waseem, 2016. Impact of training and development of employees on employee performance through job satisfaction: A study of telecom sector of Pakistan. Bus. Manage. Strategy, 7: 29-46. DOI: 10.5296/bms.v7i1.9024

Krejcie, R.V. and D.W. Morgan, 1970. Determining sample size for research activities. Educ. Psychol. Measur., 30: 607-610.

Morse, J.M., 2002. Verification strategies for establishing reliability and validity in research. J. Educ. Res., 6: 56-63.

Mozael, B.M., 2015. Impact of training and development programs on employee performance. Int. J. Scientific Res. Public., 5: 37-42.

Ng, T.W.H. and D.C. Feldman, 2009. How broadly does education contribute to job performance? Personnel Psychol., 62: 89-134.

DOI: $10.1111 /$ j.1744-6570.2008.01130.x 
Petrides, K.V. and A. Furnham, 2000. On the dimensional structure of emotional intelligence. Personality Individual Differences, 29: 313-320. DOI: 10.1016/S0191-8869(99)00195-6

Schutte, S.N., J.M. Malouff, L.E. Hall, D.J. Haggerty and J.T. Cooper et al., 1998. Development and validation of a measure of emotional intelligence. Personality Individual Differences, 25: 167-177. DOI: $10.1016 / \mathrm{S} 0191-8869(98) 00001-4$

Schwirian, P.M., 1978. Evaluating the performance of nurses: A multidimensional approach. Nurs. Res., 27: 347-351. DOI: 10.1097/00006199-197811000-00004

Sun, G., S.G. McNulty, J.A.M. Myers and E.C. Cohen, 2008. Impacts of climate change, population growth, land use change and groundwater availability on water supply and demand across the conterminous U.S. Watershed Update, 6: 1-30.
Tahir, N., I.K. Yousafzai, S. Jan and M. Hashim, 2014. The impact of training and development on employees performance and productivity: A case study of united bank limited Peshawar city, KPK, Pakistan. Int. J. Acad. Res. Bus. Soc. Sci., 4: 86-98. DOI: $10.6007 / \mathrm{IJARBSS} / \mathrm{v4}-\mathrm{i} 4 / 756$

Tiraieyari, N. and J. Uli, 2011. Moderating effects of employee gender and organizational tenure in competency-performance relationships. African J. Bus. Manage., 5: 12898-12903.

DOI: $10.5897 /$ AJBM1 1.2399

Yuxiu, P., W. Kunaviktikul and P. Thungjaroenkul, 2011. Job characteristics and job performance among professional nurses in the university hospitals of People's Republic of China. J. Nat. Sci., 10: 171-180. 